\title{
Effectiveness of muscle strengthening and description of protocols for preventing falls in the elderly: a systematic review
}

Erika Y. Ishigaki ${ }^{1}$, Lidiane G. Ramos ${ }^{1}$, Elisa S. Carvalho ${ }^{1}$, Adriana C. Lunardi ${ }^{2}$

\begin{abstract}
Background: Falls are a geriatric syndrome that is considered a significant public health problem in terms of morbidity and mortality because they lead to a decline in functional capacity and an impaired quality of life in the elderly. Lower limb muscle strengthening seems to be an effective intervention for preventing falls; however, there is no consensus regarding the best method for increasing lower limb muscle strength. Objectives: To analyze the effectiveness of lower limb muscle strengthening and to investigate and describe the protocols used for preventing falls in elderly subjects. Method: We performed a systematic review of randomized and controlled clinical trials published between 2002 and 2012 in the databases PubMed, EMBASE, Scopus, Web of Science, and PEDro that cited some type of lower limb muscle strengthening protocol and that evaluated the incidence of falls as the primary outcome exclusively in elderly subjects. Twelve studies met the inclusion criteria. Qualitative analysis was performed by independent reviewers applying the PEDro scale. Results: The data obtained from the selected studies showed lower fall rates in the intervention groups compared to controls. Six studies described the lower limb muscle strengthening protocol in detail. High methodological quality was found in 6 studies (PEDro score $\geq 7 / 10$ points). Conclusions: The methodological quality of the studies in this area appears to leave little doubt regarding the effectiveness of lower limb strengthening exercises for preventing falls in elderly subjects, however the interventions in these studies were poorly reported.
\end{abstract}

Keywords: physical therapy; elderly; falls; strength training; rehabilitation; review.

\section{HOW TO CITE THIS ARTICLE}

Ishigaki EY, Ramos LG, Carvalho ES, Lunardi AC. Effectiveness of muscle strengthening and description of protocols for preventing falls in the elderly: a systematic review. Braz J Phys Ther. 2014 Mar-Apr; 18(2):111-118. http://dx.doi.org/10.1590/ S1413-35552012005000148

\section{Introduction}

According to data from the World Health Organization (WHO), the world's population over the age of 60 will increase from 605 million to 2 billion between 2000 and $2050^{1}$. Falls in the elderly are considered one of the most serious and expensive public health problems in terms of morbidity, mortality, and enormous costs to health and social services ${ }^{2-4}$. Worldwide, about 424000 individuals die each year from falls, of which the vast majority are in low- and middle-income countries, and a further 37.3 million falls require medical attention ${ }^{1}$. Fall prevention is currently emphasized by the public health system because it is considered an indicator of the quality of service provided to the elderly ${ }^{5}$.

Falls are considered a geriatric syndrome that is associated with extrinsic and intrinsic factors. The extrinsic causes are usually related to the home environment such as rugs, stairs, and poor lighting, among others ${ }^{6}$, while the intrinsic causes are related to an impairment in balance or gait, muscle weakness, decreased visual acuity, cognitive deficits, the presence of chronic disease, postural hypotension or the use of psychotropic medication ${ }^{5,7}$.

Recent studies have shown that the most effective interventions for preventing falls are based on balance training and lower limb muscle strengthening ${ }^{8}$. The latter is considered essential for improving mobility and overall functionality. Karinkanta et al. ${ }^{9}$ showed that lower limb muscle training is important for improving functionality in elderly subjects; however, they did not assess its impact on fall prevention ${ }^{9}$. In a literature review, Cumming ${ }^{10}$ reported that exercise can help to prevent falls, but the best type of exercise was not well established. According to the authors, the exercise activities that have shown the best results so far are Tai Chi, intensive strength and endurance

\footnotetext{
${ }^{1}$ Hospital das Clínicas, Faculdade de Medicina, Universidade de São Paulo (USP), São Paulo, SP, Brazil

${ }^{2}$ Physical Therapy Department, Faculdade de Medicina, USP, São Paulo, SP, Brazil

Received: 07/15/2013 Revised: 12/21/2013 Accepted: 01/21/2014
} 
training, and home-based exercises prescribed by a physical therapist ${ }^{10}$.

In the current literature, it is difficult to find specific protocols with detailed instructions for balance and lower limb muscle training that are aimed at preventing falls. Therefore, this systematic review aimed to determine whether lower limb muscle strengthening is effective, considering the methodological quality and what exercises are most appropriate for preventing falls in the elderly.

\section{Method}

Study design: systematic review reported according to PRISMA (Preferred Reporting Items for Systematic Reviews and Meta-Analysis).

Inclusion criteria for studies: Full articles of randomized and controlled clinical trials that cited some type of lower limb muscle strengthening protocol and that evaluated the incidence of falls as the primary outcome exclusively in elderly subjects. Duplicate articles were excluded.

Search strategy and selection of studies: a search was performed in the electronic databases PubMed, EMBASE, Scopus, Web of Science, and PEDro between September 2012 and December 2012. Studies published between 2002 and 2012 were selected. The search terms used were "elderly" OR "older" AND "accident falls" OR "preventing falls" AND "exercises" OR "lower extremity" OR "limb strength", in any indexes. A second active search was performed in the reference lists of the articles that were selected in the first search to identify additional studies. We considered studies that were published in English, Portuguese, and Spanish.

Three independent reviewers examined the abstracts and contents of each study that was identified in the electronic and active searches. The studies that met all inclusion criteria were selected and re-read.

Data extraction: We standardized data extraction checking and extracting the following information from papers: study objectives; duration of treatment; follow-up; evaluation of primary outcome; participant inclusion and exclusion criteria; age; location of subject recruitment; type, duration, and frequency of intervention; and assessment of type of fall incidence.

Quality criteria: After inclusion and analysis of the studies, the three independent reviewers assessed their quality using the PEDro scale ${ }^{11}$. The PEDro scale ranges from 0 to 10 according to the following criteria: if eligibility criteria were specified; if participants were randomly allocated to groups; if allocation was concealed; if the groups were similar at baseline regarding the most important prognostic indicators; if there was blinding of all participants; if there was blinding of all therapists who administered the therapy; if there was blinding of all assessors who measured at least one key outcome; if measures of at least one key outcome were obtained from more than $85 \%$ of the patients initially allocated to groups; if there was a description of the intentionto-treat analysis; if the results of between-group statistical comparisons were reported for at least one key outcome; if the study provided both point measures and measures of variability for at least one key outcome.

The data extraction as well as the quality analysis was performed by two independent reviewers and, in case of disagreement between the reviewers, a final arbitration was performed by a third independent reviewer during a meeting.

Data analysis: Due to the high clinical heterogeneity and different outcome measurements used by the different studies, a meta-analysis approach was not possible.

\section{Results}

We found 357 articles, and 46 were selected for review. After reading the full texts, 34 articles were excluded (Figure 1), therefore 12 studies published between 2002 and 2012 were included in this analysis. Nine studies $(75 \%)$ scored more than 5 points on the PEDro Scale ${ }^{12-20}$. The most common methodological shortcomings were failure to use blind assessment (50\% of studies) $)^{13,16,18,21-23}$, no description of group randomization $(25 \%$ of studies) ${ }^{17,21,22}$, allocation of subjects was not blinded ( $25 \%$ of studies $)^{20,21,23}$, absence of initial pairing in the most important prognostic group comparisons $(16 \% \text { of studies })^{21,22}$, measuring results in less than $85 \%$ of the subjects who were included in the study (16\% of studies) $)^{22,23}$, no description of "intention to treat" ( $25 \%$ of studies $)^{18,22,23}$. and failure to provide measures of point estimates and variability for key outcomes ( $8 \%$ of studies) (Table 1$)^{22}$.

The pooled sample was composed of 3795 elderly subjects. Of these, 3260 were from the community, 96 from hospitals, and 439 from aged-care facilities (Table 2). Of the included studies, $75 \%$ used a monthly calendar to record falling episodes ${ }^{12-15,17-21}$. Only 1 study presented "falls" as the sole outcome ${ }^{22}$. Ten studies (83\%) showed a reduction in the rate of falls in the intervention group compared with other groups $^{12-17,19-22}$. Only 6 studies (50\%) described lower 


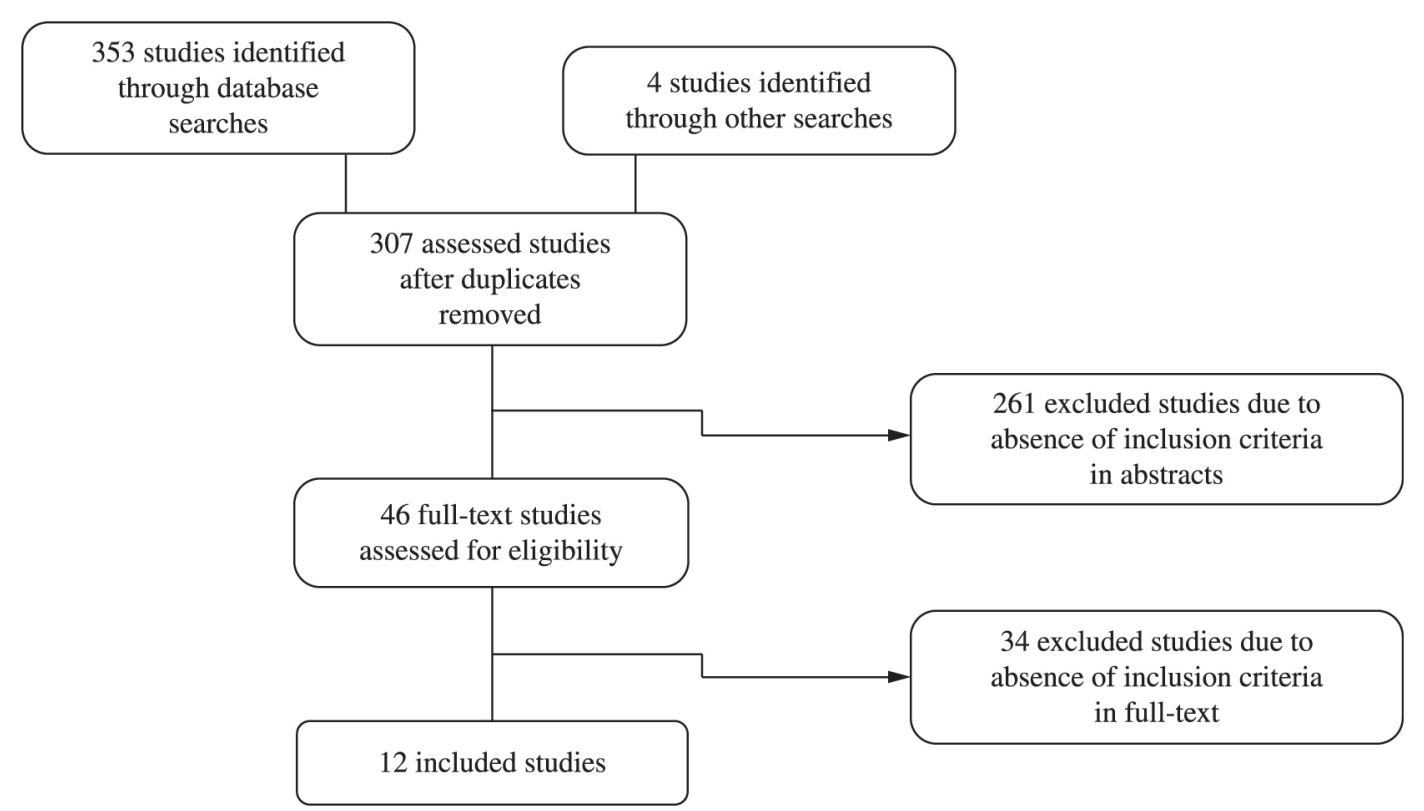

Figure 1. Flow diagram of the items involved in the systematic review.

Table 1. Assessment studies on fall prevention.

\begin{tabular}{|c|c|c|c|c|}
\hline Author (year) & Design & Aim & Outcome & PEDro \\
\hline Clemson et al. ${ }^{14}(2010)$ & $\mathrm{RCT}$ & $\begin{array}{l}\text { Investigate the feasibility and effectiveness } \\
\text { of a fall prevention program }\end{array}$ & $\begin{array}{l}\text { Falls, Balance, Strength, } \\
\text { Quality of life }\end{array}$ & $8 / 10$ \\
\hline Smulders et al. ${ }^{15}(2010)$ & $\mathrm{RCT}$ & $\begin{array}{l}\text { Evaluate the effectiveness of the Nijmegen } \\
\text { Falls Prevention Program in reducing falls } \\
\text { in the elderly with osteoporosis }\end{array}$ & Falls, Balance & $8 / 10$ \\
\hline Spink et al. ${ }^{13}(2011)$ & $\mathrm{RCT}$ & $\begin{array}{l}\text { Determine the efficacy of an intervention in } \\
\text { podiatry in prevention falls in elderly }\end{array}$ & $\begin{array}{l}\text { Falls, Strength, ROM, } \\
\text { Balance }\end{array}$ & $8 / 10$ \\
\hline Shumway-Cook et al. ${ }^{17}(2007)$ & RCT & $\begin{array}{l}\text { Evaluate the effectiveness of an intervention } \\
\text { on falls and risk factors in the elderly }\end{array}$ & Falls, Balance & $8 / 10$ \\
\hline Clemson et al. ${ }^{19}(2004)$ & $\mathrm{RCT}$ & $\begin{array}{c}\text { Verify the effectiveness of a multi-faceted } \\
\text { program for reducing falls }\end{array}$ & Falls, Strength & $7 / 10$ \\
\hline Clemson et al. ${ }^{12}$ (2012) & $\mathrm{RCT}$ & $\begin{array}{l}\text { Determine the effectiveness of strength } \\
\text { training and muscle balance in \% of falls in } \\
\text { elderly }\end{array}$ & $\begin{array}{c}\text { Falls, Strength, Balance, } \\
\text { ADL }\end{array}$ & $7 / 10$ \\
\hline Iwamoto et al. ${ }^{16}(2009)$ & $\mathrm{RCT}$ & $\begin{array}{l}\text { Investigate the effect of a training program } \\
\text { for preventing falls }\end{array}$ & $\begin{array}{l}\text { Falls, Flexibility, Balance, } \\
\text { Strength, Gait }\end{array}$ & $6 / 10$ \\
\hline Becker et al..$^{20}(2003)$ & CRT & $\begin{array}{l}\text { Evaluate the effectiveness of a multifaceted, } \\
\text { nonpharmaceutical intervention on } \\
\text { incidence of falls and fallers }\end{array}$ & Falls, Balance & $6 / 10$ \\
\hline Lord et al. ${ }^{18}(\mathbf{2 0 0 5})$ & $\mathrm{RCT}$ & $\begin{array}{l}\text { Determine if a program of individualized } \\
\text { fall prevention can reduce the risk of falls in } \\
\text { the elderly }\end{array}$ & Falls, Strength, Balance & $6 / 10$ \\
\hline Beling and Roller ${ }^{23}$ (2009) & RCT & $\begin{array}{l}\text { Measure the effectiveness of a balance } \\
\text { program on muscle strength, balance, and } \\
\text { gait in fall-prone older adults over the } \\
\text { 3-month study }\end{array}$ & Falls, Balance & $4 / 10$ \\
\hline Lord et al. ${ }^{21}(2003)$ & $\mathrm{RCT}$ & $\begin{array}{l}\text { Determine if a group exercise program can } \\
\text { improve physical functioning and reduce } \\
\text { the } \% \text { of falls in the elderly }\end{array}$ & Falls, Balance & $3 / 10$ \\
\hline Jensen et al. ${ }^{22}(2002)$ & CRT & $\begin{array}{l}\text { Investigate if a multifactorial intervention } \\
\text { program can reduce falls and injuries } \\
\text { related to falls. }\end{array}$ & Falls & $3 / 10$ \\
\hline
\end{tabular}


Table 2. Assessment of endpoints and outcomes.

\begin{tabular}{|c|c|c|c|c|}
\hline Author (year) & Subjects & $\mathbf{N}$ & Outcomes & Assessment of endpoint \\
\hline Clemson et al. ${ }^{14}(2010)$ & Community & 34 & $\begin{array}{c}\text { IG had the lowest } \% \text { of falls, better dynamic } \\
\text { balance, better MS knee, better self-efficacy } \\
\text { balance and fewer falls than CG. }\end{array}$ & monthly calendar of falls \\
\hline Smulders et al. ${ }^{15}(2010)$ & Hospital & 96 & $\begin{array}{l}\text { IG\% showed fewer falls and improved } \\
\text { balance confidence more than CG. }\end{array}$ & monthly calendar of falls \\
\hline Spink et al. ${ }^{13}(2011)$ & Community & 305 & $\begin{array}{l}\text { IG showed fewer falls, better MS, better } \\
\text { ROM, and better balance than CG. }\end{array}$ & monthly calendar of falls \\
\hline Shumway-Cook et al. ${ }^{17}(2007)$ & Community & 53 & $\begin{array}{l}\text { IG showed the lowest } \% \text { of falls, better } \\
\text { balance, better MS for the lower limbs and } \\
\text { better mobility than CG. }\end{array}$ & monthly calendar of falls \\
\hline Clemson et al. ${ }^{19}(\mathbf{2 0 0 4})$ & Community & 317 & $\begin{array}{c}\text { LIFE showed better balance and fewer } \\
\text { falls than SEG or CG; SEG and LIFE } \\
\text { showed better dynamic balance and balance } \\
\text { confidence than CG; LIFE showed more } \\
\text { improvement for MS ankle gain, ADL and } \\
\text { on the Physical Activity Scale for the Elderly } \\
\text { than CG. }\end{array}$ & monthly calendar of falls \\
\hline Clemson et al. ${ }^{12}$ (2012) & Community & 310 & $\begin{array}{l}\text { IG showed fewer falls, better confidence } \\
\text { maintenance and a greater ability to prevent } \\
\text { falls during ADL than CG. }\end{array}$ & monthly calendar of falls \\
\hline Iwamoto et al. ${ }^{16}(2009)$ & Community & 66 & $\begin{array}{l}\text { IG showed the lowest } \% \text { of falls, better } \\
\text { flexibility, better body balance, better MS and } \\
\text { better walking ability than CG. }\end{array}$ & weekly self-report \\
\hline Becker et al. ${ }^{20}(2003)$ & Community & 981 & $\begin{array}{l}\text { IG\% showed lower falls in the first and last } \\
\text { quarter of the study than CG. }\end{array}$ & monthly calendar of falls \\
\hline Lord et al. ${ }^{18}(2005)$ & Community & 620 & $\begin{array}{l}\% \text { of falls was equal in EIG, MIG, and CG. } \\
\text { EIG and MIG had better sitting and standing } \\
\text { than CG; EIG had fewer risk factors for } \\
\text { hamstring injury and higher MS than CG }\end{array}$ & monthly calendar of falls \\
\hline Beling and Roller ${ }^{23}$ (2009) & Community & 23 & $\begin{array}{l}\text { IG had fewer falls during the intervention and } \\
\text { required more ankle and knee MRIs than CG. }\end{array}$ & Self-report \\
\hline Lord et al. ${ }^{21}(2003)$ & Community & 551 & $\begin{array}{l}\text { IG showed fewer falls and better reaction time } \\
\text { for "step, step away from" than CG. }\end{array}$ & $\begin{array}{l}\text { monthly calendar and } \\
\text { recording by a nurse }\end{array}$ \\
\hline Jensen et al. ${ }^{22}(2002)$ & $\begin{array}{l}\text { Aged-care } \\
\text { facility }\end{array}$ & 439 & $\begin{array}{l}\text { IG showed lower } \% \text { of falls and lower } \% \text { of } \\
\text { femur fractures than CG; IG was greater for } \\
\text { the first fall than CG. }\end{array}$ & $\begin{array}{l}\text { self-reporting and } \\
\text { recording by a nurse }\end{array}$ \\
\hline
\end{tabular}

LIFE=Lifestyle approach to reducing Falls through Exercise; SEG=Structured Exercise Group; IG=Intervention Group; CG=Control Group; ADL=Activities of daily living; MS=Muscle Strength; ROM=Range of motion; EIG=Extensive Intervention Group; MIG=Minimal Intervention Group.

limb muscle strengthening protocols ${ }^{13,15,16,20,21,23}$ and exercises for the muscle groups surrounding the hip, knee, and ankle joints were those most frequently observed in this review (Table 3).

From all analyzed studies, 50\% used combined interventions that also affect other risk factors for falls such as vision correction, foot care, environmental adaptation, and educational activities. The reviewed protocols lasted an average of 26.5 weeks, and intervention sessions had an average frequency of 2.4 times per week. Four studies (33\%) used training with loads, and 8 studies (66\%) used functional exercises as an intervention. All of the studies that used training with loads reported a decrease in falls, and 6 of the 8 studies that used functional exercises also showed a reduction in falls ${ }^{13,15,17-20}$ (Table 3 ).

\section{Discussion}

The literature currently shows that increasing lower limb muscle strength is effective for reducing the number of falls. However, the studies analyzed 


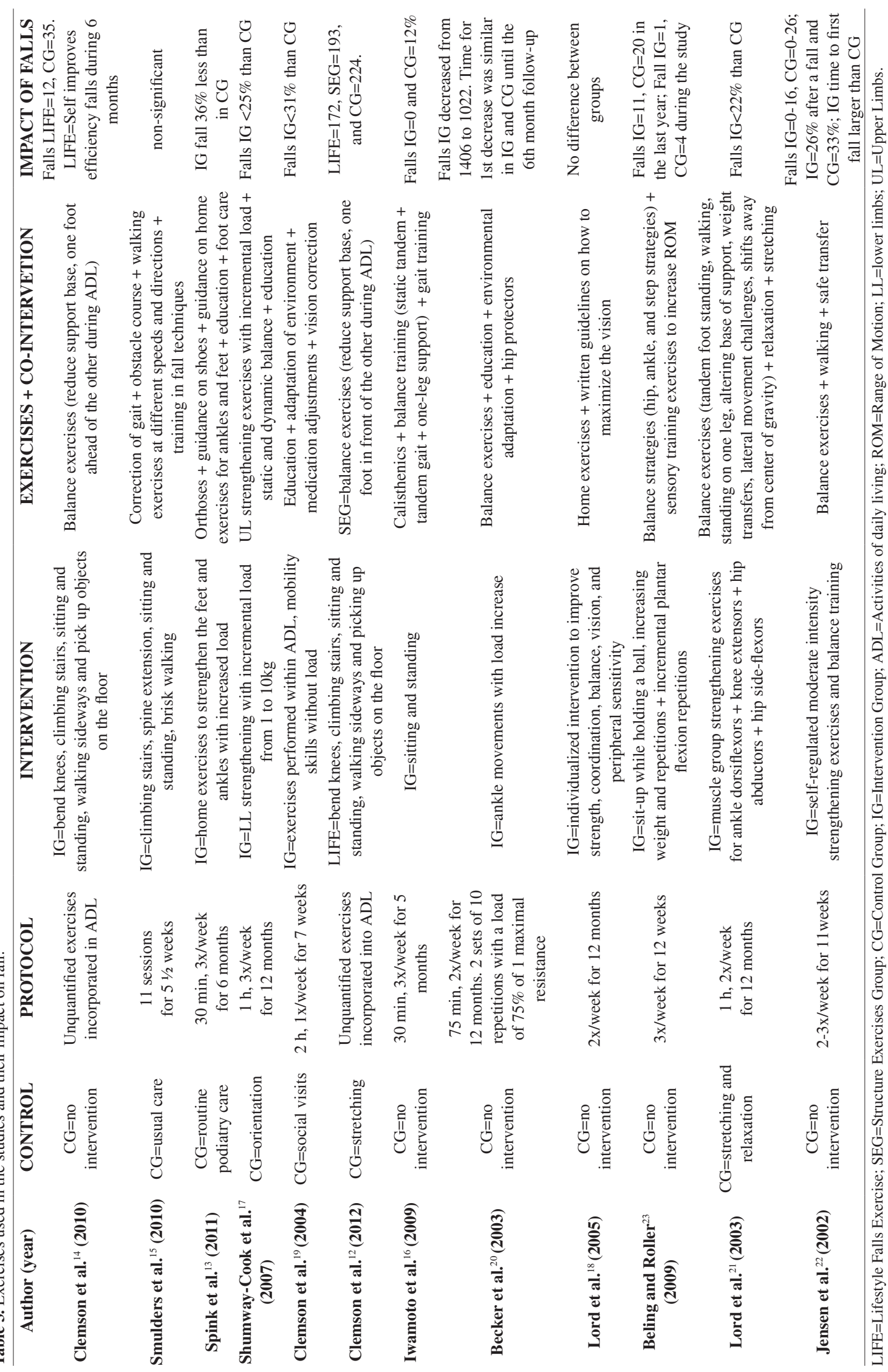


in this review did not limit themselves to muscle strengthening interventions. Many of the studies combined exercises with balance training, activities of daily living (ADL) training, gait training, and muscle stretching. Few authors described the intervention protocol in detail, and communitydwelling elderly subjects were the most frequently studied population. Additionally, most studies included in this review had high quality, and the studies with better methodological quality obtained more accurate results.

Most of the authors of the selected studies believe that lower limb muscle strengthening has an impact beyond reducing the risk of falls because the subjects that performed muscle strengthening activities showed improvement in other areas such as balance, flexibility, and functional capacity. This makes it difficult to understand the relative contribution of each fall-preventing program component ${ }^{13}$. Muscle strengthening (performed in a conventional manner or incorporated into $\mathrm{ADL}^{12,14}$ ) appears to be essential to fall prevention; all of the high-quality studies showed a reduction in falls. The most frequent exercise in the analyzed studies was the sit-to-stand exercise $(50 \%)^{12,14-16,19,23}$ because it involves an activity that subjects perform frequently in their daily lives ${ }^{24,25}$. The performance of this activity is also strongly associated with a decrease in falls. Climbing up and down steps/stairs $(33 \%)^{12,14,15,19}$ and ankle exercises $(25 \%)^{13,20,21}$ were also frequently used by the studies. Despite performing exercises such as sit-to-stand and climbing up and down steps, the subjects in one study ${ }^{15}$ showed no significant reduction in their rate of falls. Possible explanations for this result could be that the study employed the shortest time of intervention ( $5 \frac{1}{2} 2$ weeks) compared with other studies (Table 3 ) or that it included hospitalized elderly patients to create its study population. Hospitalized elderly patients are likely to present greater clinical instability and a poorer nutritional status (thus affecting muscles and exercises) than community-dwelling subjects.

Another important aspect of muscular strengthening exercises is the resistance that is used. Nearly half of the studies used incremental loads ${ }^{13,17,20,22,23}$, and $17 \%$ used only body weight ${ }^{15,19}$. The other studies did not describe if or how this type of load was used. Moreover, only the study by Becker et al. ${ }^{20}$ described in detail all of the information regarding the training program. This description is very important because different loads, frequencies, sets, number of repetitions, and time of intervention are directly related to individual strengthening responses ${ }^{26}$. Most of the authors studied in this review conducted 2 to 3 training sessions per week, an amount that is justified by the systematic review of Silva and Farinatti ${ }^{27}$ that showed a $40 \%$ average increase in muscle strength after an intervention with this frequency ${ }^{27}$. Most of the studies conducted interventions for 24 weeks or more, which is consistent with the meta-analysis of Sherrington et al. ${ }^{28}$ that showed that the ideal length of training is at least 25 weeks.

Reviewing the effectiveness of the protocols of the included studies, the optimal duration of intervention is around 6 months with a frequency of more than 2 times per week. Furthermore, training with loads seems to be more effective in preventing falls than functional exercises. The addition of co-interventions does not seem to define the effectiveness of treatment since all protocols had co-interventions, including those that had no effect on falls.

Beling and Roller $^{23}$ claim that the gold standard for the quantification of falls is daily phone calls; however, none of the studies used this form of outcome assessment. This is a potential limitation of the studies in this area because fall quantification methods remain subjective and dependent on the study population. In this review, $75 \%$ of the studies ${ }^{12-15,17-21}$ used a fall diary to measure falls, and most of the studies complemented this information with sporadic phone calls.

The target population of most of the analyzed studies was subjects over 75 years of age and, according to Lopes et al. ${ }^{29}, 30 \%$ of elderly subjects fall at least once a year and this incidence increases to between $60 \%$ and $75 \%$ in institutionalized elderly subjects. This raises the question of why the studies were conducted in individuals who are at a lower risk for falls. One hypothesis involves the greater prevalence of cognitive impairment ${ }^{30}$ and associated diseases in institutionalized elderly subjects ${ }^{31}$ because these impairments and diseases make it difficult to recruit analogous populations for protocol study control groups. Another explanation is that two systematic reviews, published in 2010 and 2012, on muscle strengthening programs for the prevention of falls in institutionalized elderly subjects showed no conclusive results because apparently the elderly subjects did not experience strength gain during the proposed interventions ${ }^{32,33}$, and factors other than muscular weakness appear to have a greater influence on the high prevalence of falls in this population ${ }^{34}$. The greatest difficulty in studying hospitalized elderly subjects may be the limited amount of time for intervention training. According to data from DATASUS, in 2012 the average hospital stay for the elderly subjects who suffered falls was 6.6 days ${ }^{1}$. 
In addition, our study shows that there was an improvement in methodological quality over time: only three articles ${ }^{21-23}$ showed a PEDro score $<5$. Among the missing items were subject randomization and group similarity, the lack of which can generate bias in the results given the heterogeneity of the groups. The findings of the studies with high methodological quality show that lower limb muscle strengthening is essential to any program aimed at preventing falls; however, some limitations of these studies can be identified. Protocols involving unconventional interventions such as Tai $\mathrm{Chi}^{35}$ and the Square-Stepping Exercise ${ }^{36}$ were excluded from this review because it was not possible to accurately discuss the techniques involved in these modalities or equate the techniques to standard techniques for muscle strengthening in elderly subjects. Furthermore, the use of these techniques depends on the therapist's specific training, which would restrict the applicability of the findings of this systematic review in clinical practice. Another difficulty was a lack of access to 3 full articles that could have been included in this review, but could not be obtained despite attempts to contact their respective authors.

The studies with high methodological quality lead us to conclude that lower limb muscle strength training is effective for preventing falls. However, this training should be accompanied by the training of other skills, such as balance and gait, and education. The interventions in these studies remain poorly reported by the authors, thus preventing the reproduction of these studies in clinical practice.

\section{References}

1. World Health Organization - WHO. WHO global report on falls prevention in older age. Geneva: WHO; 2007.

2. Cao ZB, Maeda A, Shima N, Kurata H, Nishizono H. The effect of a 12-week combined exercise intervention program on physical performance and gait kinematics in community-dwelling elderly women. J Physiol Anthropol. 2007;26(3):325-32. PMid:17641451. http://dx.doi. org/10.2114/jpa2.26.325

3. Carregaro RL, Toledo AM. Efeitos fisiológicos e evidências científicas da eficácia da fisioterapia aquática. Rev Mov. 2008;1(1):23-7.

4. Kumar SJ, Vendhan GV, Sachin A, Tiwari M, Sharma VP. Relationship between fear of falling, balance impairment and functional mobility in community dwelling elderly. Indian J Phys Med Rehabil. 2008;19(2):48-52.

5. Rubenstein LZ, Powers CM, MaClean CH. Quality indicators for the management and prevention of falls and mobility problems in vulnerable elders. Ann Intern Med. 2001;135(8):686-93. PMid:11601951. http://dx.doi. org/10.7326/0003-4819-135-8_Part_2-200110161-00007
6. Garcia RR, Gelsi TA, Sabaté ACC. A percepção dos fatores de risco para quedas em um grupo de idosas. Rev Bras Ciên Saúde. 2007;III(11):41-51.

7. Lord SR, Menz HB, Tiedemann A. A physiological profile approach to falls risk assessment and prevention. Phys Ther. 2003;83(3):237-52. PMid:12620088.

8. Gillespie LD, Robertson MC, Gillespie WJ, Lamb SE, Gates S, Cumming RG, et al. Interventions for preventing falls in older people living in the community. Cochrane Database Syst Rev. 2012;(9):CD007146. PMid:22972103.

9. Karinkanta S, Heinonen A, Sievanen H, Uusi-Rasi K, Pasanen M, Ojala K, et al. A multi-component exercise regimen to prevent functional decline and bone fragility in home-dwelling elderly women: randomized, controlled trial. Osteoporos Int. 2007;18(4):453-62. PMid:17103296. http://dx.doi.org/10.1007/s00198-006-0256-1

10. Cumming R. Intervention strategies and risk-factor modification for falls prevention - A review of recent intervention studies. Clin Geriatr Med. 2002;18(2):17589. PMID: 12180242. http://dx.doi.org/10.1016/ S0749-0690(02)00004-6

11. Maher CG, Sherrington C, Herbert RD, Moseley AM, Elkins M. Reliability of the PEDro scale for rating quality of randomized controlled trials. Phys Ther. 2003;83(8):713-21. PMid:12882612.

12. Clemson 1, Singh MAF, Bundy A, Cumming RG, Manollaras K, O'Loughlin P, et al. Integration of balance and strength training into daily life activity to reduce rate of falls in older people (the LiFE study): randomised parallel trial. BMJ. 2012;345:e4547. PMid:22872695 PMCid:PMC3413733. http://dx.doi.org/10.1136/bmj. e4547

13. Spink MJ, Menz HB, Fotoohabadi MR, Wee E, Landorf $\mathrm{KB}$, Hill KD, et al. Effectiveness of a multifaceted podiatry intervention to prevent falls in community dwelling older people with disabling foot pain: randomized controlled trial. BMJ. 2011;16:342-40. http://dx.doi.org/10.1136/ bmj.d3411

14. Clemson L, Singh MF, Bundy A, Cumming RG, Weissel E, Munro J, et al. LiFE pilot study: a randomised trial of balance and strength training embedded in daily life activity to reduce falls in older adults. Aust Occup Ther J. 2010;57(1):42-50. PMid:20854564. http://dx.doi. org/10.1111/j.1440-1630.2009.00848.x

15. Smulders E, Weerdesteyn V, Groen BE, Duysens J, Eijsbouts A, Laan R, et al. Efficacy of a short multidisciplinary falls prevention program for elderly persons with osteoporosis and a fall history: a randomized controlled trial. Arch Phys Med Rehabil. 2010;91(11):1705-11. PMid:21044715. http://dx.doi.org/10.1016/j.apmr.2010.08.004

16. Iwamoto J, Suzuki H, Tanaka K, Kumakubo T, Hirabayashi H, Miyazaki Y, et al. Preventative effect of exercise against falls in the elderly: a randomized controlled trial. Osteoporos Int. 2009;20(7):1233-40. PMid:19011727. http://dx.doi.org/10.1007/s00198-008-0794-9

17. Shumway-Cook A, Silver IF, Lemier M, York S, Cummings P, Koepsell TD. Effectiveness of a communitybased multifactorial intervention on falls and fall risk factors in community-living older adults: a randomized, controlled trial. J Gerontol A Biol Sci Med Sci. 
2007;62(12):1420-7. PMID: 18166695. http://dx.doi. org/10.1093/gerona/62.12.1420

18. Lord SR, Tiedemann A, Chapman K, Munro B, Murray SM, Gerontology M, et al. The effect of an individualized fall prevention program on fall risk and falls in older people: a randomized, controlled trial. J Am Geriatr Soc. 2005;53(8):1296-304. PMid:16078954. http://dx.doi. org/10.1111/j.1532-5415.2005.53425.x

19. Clemson L, Cumming RG, Kendig H, Swann M, Heard R, Taylor K. The Effectiveness of a communitybased program for reducing the incidence of falls in the elderly: a randomized trial. J Am Geriatr Soc. 2004;52(9):1487-94. PMid:15341550. http://dx.doi. org/10.1111/j.1532-5415.2004.52411.x

20. Becker C, Kron M, Lindemann U, Sturm E, Eichner B, Walter-Jung B, et al. Effectiveness of a multifaceted intervention on falls in nursing home residents. J Am Geriatr Soc. 2003;51(3):306-313. PMid:12588573. http:// dx.doi.org/10.1046/j.1532-5415.2003.51103.x

21. Lord SR, Castell S, Corcoran J, Dayhew J, Matters B, Shan A, et al. The effect of group exercise on physical functioning and falls in frail older people living in retirement villages: a randomized, controlled trial. J Am Geriatr Soc. 2003;51(12):1685-92. PMid:14687345. http:// dx.doi.org/10.1046/j.1532-5415.2003.51551.x

22. Jensen J, Lundin-Olsson L, Nyberg L, Gustafson Y. Fall and Injury Prevention in Older People Living in Residential Care Facilities: a cluster randomized trial. Ann Intern Med. 2002;21;136(10):733-41. PMid:12020141.

23. Beling J, Roller M. Multifactorial Intervention with Balance Training as a Core Component Among Fall-Prone Older Adults. J Geriatri Phys Ther. 2009;32(3):125-133. PMID: 20128337. http://dx.doi. org/10.1519/00139143-200932030-00008

24. Roorda LD, Roebroeck ME, Lankhorst GJ, Tilburg TV, Bouter LM. Measuring functional limitations in rising and sitting down: development of a questionnaire. Arch Phys Med Rehabil. 1996;77(7):663-9. PMID: 8669992. http:// dx.doi.org/10.1016/S0003-9993(96)90005-2

25. Lira VA, Araújo CGS. Teste de sentar-levantar: estudos de fidedignidade. Rev Bras Ciên Mov. 2000;8(2):9-18.

26. Frontera WR, Meredith CN, O'Reilly KP, Knuttgen HG, Evans WJ. Strength conditioning in older men: skeletal muscle hypertrophy and improved function. J Appl Physiol. 1988;64(3):1038-44. PMid:3366726.

27. Silva NL, Farinatti PTV. Influência de variáveis do treinamento contra-resistência sobre a força muscular de idosos: uma revisão sistemática com ênfase nas relações dose-resposta. Rev Bras Med Esporte. 2007;13(1):60-6. http://dx.doi.org/10.1590/S1517-86922007000100014

28. Sherrington C, Whitney JC, Lord SR, Herbert RD, Cumming RG, Close JCT. Effective exercise for the prevention of falls: a systematic review and meta-analysis.
J Am Geriatr Soc. 2008;56(12):2234-43. PMid:19093923 . http://dx.doi.org/10.1111/j.1532-5415.2008.02014.x

29. Lopes MNSS, Passerini CG, Travensolo CF. Eficácia de um protocolo fisioterapêutico para equilíbrio em idosos institucionalizados. Semina Cienc Biol Saude. 2010;31(2):143-52. http://dx.doi. org/10.5433/1679-0359.2011v32n2p143

30. Converso MER, Iartelli I. Caracterização e análise do estado mental e funcional de idosos institucionalizados em instituições públicas de longa permanência. J Bras Psiquiatr. 2007;56(4):265-72. http://dx.doi.org/10.1590/ S0047-20852007000400005

31. Aires M, Paz AA, Perosa CT. O grau de dependência e características de pessoas idosas institucionalizadas. Rev Bras Ciênc Envelhec Hum. 2006;3(2):79-91.

32. Cameron ID, Murray GR, Gillespie LD, Robertson MC, Hill KD, Cumming RG, et al. Interventions for preventing falls in older people in nursing care facilities and hospitals. Cochrane Database Syst Rev. 2010;(7):CD005465. PMid:20091578.

33. Cameron I, Gillespie L, Robertson M, Murray GR, Hill $\mathrm{KD}$, Cumming RG, et al. Interventions for preventing falls in older people in care facilities and hospitals. Cochrane Database Syst Rev. 2012;12:Cd005465. PMid:23235623.

34. Damián J, Pastor-Barriuso R, Valderrama-Gama E, De Pedro-Cuesta J. Factors associated with falls among older adults living in institutions. BMC Geriatr. 2013;13:6-15. PMid:23320746 PMCid:PMC3566955. http://dx.doi. org/10.1186/1471-2318-13-6

35. Taylor D, Hale L, Schluter P, Waters DL, Binns EE, McCracken H, et al. Effectiveness of Tai Chi as a community-based falls prevention intervention: a randomized controlled trial. J Am Geriatr Soc. 2012;60(5):841-8. PMid:22587850. http://dx.doi org/10.1111/j.1532-5415.2012.03928.x

36. Shigematsu R, Okura T, Nakagaichi M, Tanaka K, Sakai $\mathrm{T}$, Kitazumi S, et al. Square-Stepping exercise and fall risk factors in older adults: a single-blind, randomized controlled trial. PMID: 18245764. J Gerontol A Biol Sci Med Sci. 2008;63(1):76-82. http://dx.doi.org/10.1093/ gerona/63.1.76

\section{Correspondence}

\section{Adriana C. Lunardi}

Universidade de São Paulo

Faculdade de Medicina

Departamento de Fisioterapia

Rua Cipotânea, 53

CEP 05360-000, São Paulo, SP, Brazil

e-mail: adrianalunardi@usp.br 